\title{
PENGARUH KOMUNIKASI INTERPERSONAL DAN LINGKUNGAN KERJA TERHADAP KINERJA KARYAWAN (Studi Pada Karyawan F\&B Departement ASTON Cirebon Hotel \& Convention Center Kabupaten Cirebon)
}

\author{
Yuniar Sari Ratna Puri, Ratih Hurriyati, Rini Andari \\ Program Studi Manajemen Industri Katering \\ Fakultas Pendidikan Ilmu Pengetahuan Sosial \\ Universitas Pendidikan Indonesia \\ yuniarsariratnap@yahoo.id
}

\begin{abstract}
ABSTRAK
Penelitian ini dilatarbelakangi oleh permasalahan yang timbul pada ASTON Cirebon Hotel \& Convention Center, yaitu mengenai komunikasi interpersonal, lingkungan kerja dan kinerja karyawan di perusahaan ini kurangnya kesadaran karyawan dalam berkomunikasi dengan sesama karyaawan mengenai pekerjaaan mereka, serta kurangnya rasa inisiatif dalam melaksanakan ataupun menyelesaikan tugas mereka. Oleh karena itu penulis melakukan penelitian tentang pengaruh komunikasi interpersonal daan lingkungaan kerja terhaadap kinerja karyawan.

Penelitian ini menggunakan metode kuantitatif, yaitu deskriptif dan verifikatif. Sampel dalam penelitian ini adalah karyawan dari departemen Food and Beverage di AASTON Cirebon Hotel \& Convention Center. Pengambilaan sampel sejumlah 60 orang yang dilaksanakan pada bulan Agustus 2015. Teknik pengumpulan data pada penelitian ini menggunakan kuisoner yang disebar kepada sampel.

Hasil dari penelitian ini adalah adanya pengaruh yang signifikan antara komunikasi interpersonal dan lingkungan kerja terhadap kinerja karyawan. Besarnya pengaruh komunikasi terhadap kinerja sebesar 6,25\% sedangkan lingkungan kerja terhadap kinerja sebesar $4,24 \%$, dari penelitian ini dapat disimpulkan bahwa ada pengaruh positif antara komunikasi interpersonal dan lingkungan kerja terhadap kinerja karyawan walaupun kadar pengaruh pada variabel-variabel tersebut tidak menunjukan hasil yang besar.
\end{abstract}

Kata kunci: Komunikasi Interpersonal, Lingkungan Kerja, Kinerja Karyawan

\section{PENDAHULUAN}

Indonesia memiliki sumber daya pariwisata yang tidak kalah menariknya bila dibandingkan dengan negara lain di ASEAN, tempat wisata di Indonesia memiliki banyak kekayaan alam yang indah peninggalan sejarah (heritage), budaya, serta ekowisatanya. Tempat-tempat wisata tersebut dapat menarik para wisatawan mancanegara maupun lokal untuk berkunjung ke tempat wisata yang berada di Indonesia. Salah satu daerah di Indonesia yang menawarkan pariwisatanya peninggalan sejarah dan budayanya adalah kabupaten Cirebon yang terletak di Provinsi Jawa Barat. Kabupaten Cirebon menawarkan berbagai macam tempat wisata yang bernilai sejarah yaitu makam Sunan Gunung Jati, makam Nyimas Gandasari, objek wisata Plangon, Belawa, serta menawarkan, di Kab. Cirebon pula menawarkan 
makanan khas dan oleh-oleh khas Cirebon yaitu batik mega mendung untuk melengkapi para wisatawan yang berwisata ke Kab.Cirebon.

Pada saat ini Kab. Cirebon terus mengalami data perkembangan di bidang pariwisatanya yaitu dapat dilihat pada data kunjungan wisatawan di Kab.Cirebon yang terus mengalami peningkatan

TABEL 1.1

\section{DATA KUNJUNGAN WISATAWAN DI KAB.CIREBON} PERIODE 2010-2014

\begin{tabular}{|c|c|c|c|}
\hline Tahun & $\begin{array}{c}\text { Wisatawan } \\
\text { mancanegara }\end{array}$ & $\begin{array}{c}\text { Wisatawan } \\
\text { nusantara }\end{array}$ & $\begin{array}{c}\text { Jumlah } \\
\text { wisatawan }\end{array}$ \\
\hline 2010 & 159 & 483.521 & 483.680 \\
\hline 2011 & 175 & 675.279 & 675.454 \\
\hline 2012 & 136 & 583.008 & 583.144 \\
\hline 2013 & 1.914 & 795.42 & 797.375 \\
\hline 2014 & 3.167 & 590.964 & 594.131 \\
\hline
\end{tabular}

Sumber: Dinas Pemuda Olahraga Kebudayaan dan Pariwisata Kab.Cirebon tahun 2014

Berdasarkan data di atas dapat dilihat bahwa minat wisatawan yang berkunjung ke kabupaten Cirebon setiap tahunnya selalu ramai ini didasarkan oleh terus berkembangnya sarana dan prasarana penunjang pariwisata, seperti jumlah akomodasi yang terus bertambah yaitu akomodasi hotel. Akomodasi hotel yang terdapat di Kab.Cirebon pun bervariasi mulai dari hotel melati hingga hotel yang berbintang, karena akomodasi sangat diperlukan pada sektor pariwisata. Terdapat banyaknya hotel di Kabupaten Cirebon penulis mengambil objek yaitu ASTON Cirebon Hotel \& Convention Center, karena hotel ASTON ini masih terbilang baru di kabupaten Cirebon yaitu berdiri pada tahun 2012 namun selalu ramai dikunjungi setiap hari karena bukan hanya menyediakan kamar saja tetapi hotel ini juga menyediakan fasilitas lainnya setara dengan bintang empat. ASTON Cirebon Hotel \& Convention Center terletak di jalan Brigjen Dharsono No.12C, yang termasuk ke dalam tempat yang strategis untuk ke pusat Kota Cirebon.

Banyaknya para wisatawan yang di ASTON Cirebon Hotel \& Convention Center untuk itu diperlukan Sumber daya manusia yang dapat memuaskan para wisatawan yang menginap di ASTON Cirebon Hotel \& Convention Center untuk itu diperlukan karyawan yang mempunyai SDM yang bagus dan giat dalam bekerja karena SDM yang baik merupakan asset yang dapat meningkatkan keberhasilan perusahaan, kemampuan SDM merupakan kunci utama perusahaan untuk mampu menghadapi persaingan, namun pada kenyataannya karyawan ASTON Cirebon hotel \& Convention center masih kurang disiplin, Berdasarkan data dari perusahaan bahwa tingkat ketidak hadiran karyawan ASTON Cirebon Hotel \& Convention Center masing- masing yaitu sekitar 11 hari perkaryawan dan itu terdapat pada Department F\&B. Selain masalah ketidakhadiran masalah keterlambatan karyawan merupakan salah satu faktor yang mempengaruhi kinerja karyawan, dari data perusahaan selama periode 26 November 2014 hingga 25 Maret 2015 karyawan ASTON merupakan karyawan yang kurang disiplin itu dengan jumlah waktu keterlambatan rata-rata 1 
jam hingga 3 jam 80 menit perkaryawan setiap bulannya. Namun yang paling tinggi keterlambatan melihat dari data perusahaan adalah F\&B Department dengan rata-rata 1,44 jam hingga 3,80 jam perkaryawan. Oleh sebab itu peneliti tertarik untuk mengadakan pra penelitian di F\&B Department dan hasilnya adalah.

Melihat pada hasil pra penelitian di atas jawaban menunjukan hubungan rekan kerja dengan lingkungan kerja. Hubungan baik dengan rekan kerja adalah salah satu syarat yang dibutuhkan untuk menghasilkan kinerja yang efektif dan kreatif serta berkualitas dalam organisasi. Berdasarkan latar belakang penelitian tersebut maka penulis tertarik untuk mengadakan penelitian lebih lanjut di F\&B departement ASTON Cirebon Hotel \& Convention Center dengan judul "PENGARUH KOMUNIKASI INTERPERSONAL DAN LINGKUNGAN KERJA TERHADAP KINERJA KARYAWAN"

\section{Tujuan Penelitian}

1. Bagaimana gambaran Komunikasi interpersonal pada karyawan F\&B Departement ASTON Cirebon Hotel \& Convention Center.

2. Bagaimana gambaran lingkungan kerja pada karyawan F\&B Departement ASTON Cirebon Hotel \& Convention Center.

3. Bagaimana gambaran kinerja karyawan pada karyawan F\&B Departement ASTON Cirebon Hotel \& Convention Center.

4. Bagaimana pengaruh komunikasi interpersonal dan lingkungan kerja terhadap kinerja karyawan pada karyawan F\&B Departement ASTON Cirebon Hotel \& Convention Center

\section{Metode penelitian}

Berdasarkan variabel-variabel yang diteliti, maka penulis menggunakan jenis penelitian deskriptif dan verifikatif. Penelitian deskriptif diambil untuk memproleh gambaran mengenai pengaruh hubungan interpersonal dan lingkungan kerja terhadap kinerja karyawan F\&B Department ASTON Cirebon Hotel \& Convention Center, sedangkan penelitian verifikatif merupakan mencari sesuatu kebenaran dari suatu hipotesis yang dilaksanakan melalui pengumpulan data dilapangan. Pengambilan data pada metode ini dengan menggunakan kuisioner

Operasional variabel merupakan bagian yang mendefinisikan sebuah konsep atau variabel agar dapat diukur, dengan cara melihat pada dimensi (indikator) dari suatu konsep atau variabel. Dimensi (indikator) dapat berupa: perilaku, aspek, atau sifat/karakteristik. Sekaran (dalam Noor, 2013, hlm.97).

Operasional variabel dimaksudkan untuk mengetahui pengaruh pengukuran variabel-variabel penelitian. Dalam penelitian ini penulis mengemukakan tiga variabel yang akan diteliti. Adapun variabel yang akan diteliti pada penelitian ini adalah dua variabel independent yaitu komunikasi interpersonal (X1) dan Lingkungan kerja (X2), dan variabel dependent pada penelitian ini adalah kinerja karyawan $(\mathrm{Y})$.

Skala pengukuran dalam penelitian ini menggunakan skala interval. Skala interval mempunyai karakteristik seperti yang dimiliki oleh skala nominal dan ordinal 
dengan ditambah karakteristik lain, yaitu berupa interval yang tetap. skla pengukuran ini menggunakan statistik parametrik. Noor (2013, hlm.127)

Teknik pengumpulan data pada penelitian ini adalah menggunakan

a. Kuisioner / Angket

b. Observasi

c. Dokumen

d. Studi literatur

Jenis analisis data pada penelitian ini yaitu menggunakan kuantitatif. Teknik analisis data pada penelitian kuantitatif menggunakan statistik, pada statistik infrensial menggunakan statistik parametris, statistik parametris digunakan untuk menguji parameter populasi melalui statistik, atau menggunakan ukuran populasi melalui sampel, statistik parametris kebanyakan digunakan untuk menganalisis data interval dan ratio.

Bentuk hipotesis pada penelitian ini yaitu menggunakan hipotesis deskriptif dan assosiatif. Hipotesis assosiatif adalah dugaan terhadap ada tidaknya hubungan secara signifikan antara dua variabel atau lebih. Aplikasi yang digunakan mengolah data pada penelitian ini adalah menggunakan aplikasi SPSS.

\section{Uji Korelasi ganda}

Rumus:

$$
R \quad Y X 1 X 2=\sqrt{\frac{r_{y x 1^{2}+r y x 2^{2} 2 r_{y x 1} r_{y x 2} r_{x 1 x 2}}^{1-r_{x 1 x 2^{2}}}}{r^{2}}}
$$

Dimana :

$R_{Y X 1 X 2}=$ Korelasi antara variabel $\mathrm{X} 1$ dengan $\mathrm{X} 2$ secara bersama-samadengan variabel Y

$r_{y x 1}=$ Korelasi Product moment antara X1 dengan $\mathrm{Y}$

$r_{y x 2}=$ Korelasi Product moment antara X2 dengan $\mathrm{Y}$

$r_{X 1 X 2}=$ Korelasi Product moment antara X1 dengan X2

Untuk mengetahui tingkat hubungan kedua variabel tersebut maka dapat dilihat pada tabel 3.11

TABEL 1.3

PEDOMAN UNTUK MEMBERIKAN INTERPRESTASI TERHADAP KOEFISIEN KORELSI

\begin{tabular}{|c|c|}
\hline Interval koefisien & $\begin{array}{c}\text { Tingkat } \\
\text { Hubungan }\end{array}$ \\
\hline $0,00-0,199$ & Sangat rendah \\
\hline $0,20-0,399$ & Rendah \\
\hline $0,40-0,599$ & Sedang \\
\hline $0,60-0,799$ & Kuat \\
\hline $0,80-1,000$ & Sangat kuat \\
\hline
\end{tabular}

Sumber: Sugiyono(2014:231)

\section{Uji Regresi ganda}


Analisis regresi ganda akan dilakukan bila jumlah variabel independenya minimal 2. Persamaan regresi ganda.

$$
Y=a+b_{1} x_{1}+b_{2} x_{2}
$$

Dimana :

$\mathrm{Y}=$ Kinerja karyawan

$\mathrm{X} 1=$ Komunikasi interpersonal

$\mathrm{X} 2=$ Lingkungan kerja

a $\quad=$ Harga $\mathrm{Y}$ apabila $\mathrm{X}=0$ (Harga konstan)

b1b2 =koefisien regresi yang menunjukan peningkatan atau penurunan variabel dependen yang didasarkan pada variabel independen. Bila b (+) maka naik, bila $b(-)$ maka terjadi penurunan.

\section{Uji hipotesis}

Hipotesis adalah suatu pernyataan yang menunjukkan dugaan tentang hubungan antara dua variabel atau lebih. Sugiyono (2014:89)

Rumus yang digunakan penulis untuk menguji hipotesis yaitu uji $\mathrm{t}$

Rumusan uji $\mathrm{t}$

$\mathrm{t}=\frac{r \sqrt{n-2}}{\sqrt{1-r^{2}}}$

keterangan: $\quad t=$ Distribusi student

$\mathrm{r}^{2}=$ koefisien korelasi dan uji indepndent

$\mathrm{n}=$ banyaknya sampel

Selain menggunakan uji t pada hipotesis penulis pun menggunakan uji $\mathrm{f}$

uji F. $F h=\frac{R^{2} / k}{\left(1-R^{2}\right) /(n-k-1)}$

$\mathrm{R}=$ koefisien korelasi ganda

$\mathrm{k}=$ jumlah variabel independent

$\mathrm{n}=$ jumlah anggota sampel

Analisi korelasi

Analisis korelasi digunakan untuk mengetahui atau mencari hubungan dan membuktikan hipotesis hubungan dua variabel bila data kedua variabel berbentuk interval. Sugiyono (2014, hlm.228) .

\section{Pembahasan}

\section{Pembahasan pengaruh komunikasi interpersonal terhadap kinerja}

Komunikasi atau hubungan interpersonal dapat mempengaruhi kinerja karyawan yaitu menambah semangat kerjasama yang produktif ini dikemukakan oleh Suranto (2011, hlm.28) Dan kedisiplinan yang timbul dalam diri karyawan itu berasal dari hubungan dan komunikasi yang baik diantar sesama karyawan dan pemimpin. Terciptanya human relationship yang serasi akan mewujudkan lingkungan dan suasana yang nyaman. Hasibuan (2007, hlm.198) Kedisiplinan yang tinggi memotivasi karyawannya untuk lebih giat lagi dalam menjalankan pekerjaan dan karyawan yang disiplin tercipta dari komunikasi dan hubungan yang harmonis di dalam perusahaan. Berdasarkan hasil penelitian secara empiris dan teoritis bahwasannya terdapat pengaruh yang positif komunikasi interpersonal terhadap kinerja karyawan di departement F\&B ASTON Cirebon Hotel \& Convention Center 


\section{Pembahasan lingkungan kerja terhadap kinerja}

Lingkungan kerja sangat mempengaruhi kinerja karyawan, apabila diantaranya ditunjang oleh suatu kondisi lingkungan yang sesuai. Suatu kondisi dikatakan baik atau sesuai apabila manusia dapat melaksanakan kegiatannya secara optimal, sehat, aman dan nyaman keadaan lingkungan yang kurang baik dapat menuntut tenaga dan waktu yang lebih banyak dan tidak mendukung diperolehnya rancangan sistem kerja yang efesien. Sedarmayanti (2011, hlm.28) Dan kinerja sangat dipengaruhi lingkungan kerja yakni pengendalian suatu perusahaan untuk mengendalikan karyawannya dan melaksanakan tugasnya. Hasibuan (2007, hlm.22) Berdasarkan hasil penelitian teori dan empiris bahwasannya terdapat pengaruh positif lingkungan kerja terhadap kinerja yang tidak bisa dibantah.

\section{Pembahasan lingkungan kerja dan komunikasi interpersonal terhadap kinerja}

Secara teori lingkungan kerja dan komunikasi interpersonal merupakan bagian fungsi dari MSDM yitu menurut Hasibuan (2007, hlm.22), sehingga lingkungan dan komunikasi mempengaruhi kinerja. Menurut Hasibuan (2007, hlm.137) mengatakan bahwa hubungan atau komunikasi interpersonal akan tercipta serta terpelihara dengan baik jika ada kesediaan melebur sebagian keinginan individu demi tercapainya kepentingan bersama yang didasarkan atas saling pengertian, harga menghargai, hormat-menghormati, toleransi, menghargai pengorbanan, dan peranan yang diberikan setiap individu anggota kelompok karyawan. Tujuan dari itu adalah mendorong kerjasama yang produktif dan kreatif untuk mencapai sasaran atau target dari perusahaan lingkungan apabila di antaranya ditunjang oleh suatu kondisi lingkungan yang sesuai,suatu kondisi lingkungan kerja dikatan baik atau sesuai apabila manusia (karyawan) dapat melaksanakan kegiatannya secara optimal, sehat, aman dan nyaman ketidak sesuain lingkungan kerja dapat dilihat dari kinerja karyawannya. Sedarmayanti (2011, hlm.27) Lingkungan kerja pun mempengaruhi kinerja karena lingkungan kerja dijadikan untuk pengendalian karyawan dalam melaksanakan pekerjaannya. Hasibuan (2007, hlm.22) Dengan demikian hubungan antar komunikasi interpersonal (X1), lingkungan kerja (X2) dan Kinerja (Y) sudah tidak terbantahkan baik secara empiris, maupun teoritis, namun secara empiris komunikasi interpersonal (X1), lingkungan kerja (X2) dan Kinerja (Y) secara bersama-sama berpengaruh rendah tetapi pada kenyataannya masih terdapat hubungan yang positif antara tiga variabel tersebut. Disimpulkan bahwa terdapat pengaruh yang positif antara komunikasi interpersonal (X1), lingkungan kerja (X2) dan Kinerja (Y) di ASTON Cirebon Hotel \& Convention Center F\&B departement

\section{Kesimpulan}

Berdasarkan hasil penelitian yang dilakukan di ASTON Cirebon Hotel \& Convention Center F\&B departement mengenai pengaruh komunikasi interpersonal dan lingkungan kerja terhadap kinerja karyawan ASTON Cirebon Hotel \& Convention Center F\&B departement maka dapat ditarik kesimpulannya adalah:

1. Tingkat komunikasi interpersonal ASTON Cirebon Hotel \& Convention Center F\&B departement berada pada kategori cukup tinggi, namun harus tetap dijalin hubungan kekerabatan dan rasa saling mendukung dengan antar karyawan maupun pemimpin, agar dapat membantu para pekerja dalam 
menyelesaikan pekerjaan dengan dukungan sesama pekerja yang dapat menambah rasa semangat pada diri individu.

2. Tingkat Lingkungan kerja di ASTON Cirebon Hotel \& Convention Center F\&B departement berada pada kategori tinggi. Yang artinya bahwa lingkungan kerja di ASTON Cirebon Hotel \& Convention Center F\&B departement sudah baik dan dapat menunjang karyawan dalam menjalankan pekerjaannya

3. Tingkat Kinerja karyawan di ASTON Cirebon hotel \& convention center departemen F\&B berada pada kategori tinggi, artinya para karyawan di ASTON Cirebon Hotel \& Convention Center F\&B departement sudah menjalankan kewajiban mereka dengan baik.

4. Berdasarkan hasil penelitian secara empiris dan teoritis bahwasannya terdapat pengaruh yang positif antar komunikasi interpersonal dan lingkungan kerja terhadap kinerja karyawan di ASTON Cirebon hotel \& convention departemen F\&B secara bersama-sama berpengaruh rendah namun kenyataannya masih terdapat hubungan yang positif antara tiga variabel tersebut.

\section{DAFTAR PUSTAKA}

AW Suranto.2011.KOMUNIKASI INTERPERSONAL.Yogyakarta:Graha Ilmu Hasibuan Malayu.2007.Manajemen Sumber Daya Manusia.Jakarta:PT.Bumi Aksara

Kaswan.2012.Manajemen Sumber Daya Manusia Untuk Unggulan Bersaing.Yogyakarta:Graha ilmu

Noor Juliansyah.2013.METODOLOGI PENELITIAN Skripsi, Tesis, Disertasi, dan karya Ilmiah.Jakarta:Kencana

Sambodo Agus \& Bagyo.2006.Dasar-dasar depan hotel.Yogyakarta:CVAndi offset Sedarmayanti.2011.Tata kerja dan Produktivitas kerja.Bandung:Cv Mandjar maju Siregar syofian.2013.Statistik Parametic untuk penelitian kuantitatif dilengkapi dengan perhitungan manual aplikasi SPSS Versi 17.Jakarta:Bumi Aksara

Rejeki Sri.2015. Sanitasi Hygiene dan K3(Kesehatan dan Keselamatan Kerja). Bandung. Rekayasa Sains

Rosady Ruslan.2013.Metode penelitian public relations dan komunikasi.Jakarta:PT.Raja Grafindo persada

Sugiyono.2010.Statistik untuk penelitian.Bandung:Alfabeta

Sugiyono.2012.Statistik untuk penelitian.Bandung:Alfabeta

Sugiyono.2014.Statistik untuk penelitian.Bandung:Alfabeta

Wibowo.2007.Manajemen Kinerja

Jurnal:

Wulan Lucky dan Mudji Rahardjo.Analisa pengaruh Motivasi kerja dan Lingkungan kerja terhadap kinerja karyawan (studi pada dinas perindustrian dan perdagangan kota Semarang).Semarang:UNDIP Repository[online].tersedia:eprints.Undip.ac.id/26826/1/jurnal-skripsi 